\title{
Challenges and opportunities of sensory plasticity after SCl
}

\author{
Jeffrey C. Petruska ${ }^{1}{ }^{*}$, Charles H. Hubscher ${ }^{1}$ and Alexander G. Rabchevsky ${ }^{2}$ \\ ${ }^{1}$ Department of Anatomical Sciences and Neurobiology, Kentucky Spinal Cord Injury Research Center, University of Louisville, Louisville, KY, USA \\ ${ }^{2}$ Department of Physiology, Spinal Cord and Brain Injury Research Center, University of Kentucky, Lexington, KY, USA \\ ${ }^{*}$ Correspondence: j.petruska@louisville.edu
}

Edited by:

Geoffrey A. Head, Baker IDI Heart and Diabetes Institute, Australia

Keywords: spinal cord injury (SCI), sensory plasticity, sensory perceptions, sensory neurons, sensory systems

Even in cases of spinal cord injury (SCI) where sensory perceptions do not arise from stimuli applied to below-level regions, sensory input to the spinal cord, carried by spinal sensory afferents, still occurs and influences the central and autonomic nervous systems (CNS, ANS). This is true also of the vagal system which provides non-spinal innervation of viscera below many spinal cord injuries. It is therefore important to consider (1) how the neurochemical, anatomical, and electrophysiological properties of these sensory neurons, and the processing of the inputs by the CNS and ANS, is altered by SCI, (2) whether and how they may play a role in pathologies, and (3) how they may interact with treatment strategies. This Research Topic addresses plasticity of sensory systems after SCI, with a non-exclusive focus on systems below the level of the injury.

\section{POST-SCI AUTONOMIC DYSFUNCTIONS}

The ANS controls systems below the level of consciousness and this is often taken for granted until something goes awry. Those living with SCI are acutely aware of the functions regulated, or more often dysregulated, by the ANS. One of the most pressing of these issues is autonomic dysreflexia (AD), a chronic and common hypertensive syndrome essentially unique to the high-level SCI community. It rarely arises acutely after injury (Krassioukov et al., 2003; Krassioukov, 2004), suggesting mechanisms beyond just loss of spinal sympathetic outflow regulation by the brain, and experimental evidence suggests that various forms of plasticity in numerous cell-types may contribute (e.g., Taylor and Schramm, 1987; Chau et al., 2000; Teasell et al., 2000; Rabchevsky, 2006; Schramm, 2006; Brown and Weaver, 2012). AD is generally considered an episodic pathology with bouts initiated and maintained by a physiological trigger, and is treated symptomatically and by finding and removing the stimulus. Continuing refinements in our understanding and measurements suggest that the severe clinical bouts that garner the most attention may be the tip of the iceberg of a much more insipid and persistent condition (e.g., Claydon et al., 2006; Krassioukov and Claydon, 2006). The most frequent triggers of $\mathrm{AD}$ appear to be noxious stimuli below the injury level [anything from a full bladder, an impacted bowel or a pressure ulcer to an ingrown toenail or simply having new shoes tied too tightly (e.g., Krassioukov et al., 2009)], placing focus onto plasticity in nociceptive sensory neurons (Ramer et al., 2012) for identifying potential mechanisms and treatments (Rabchevsky et al., 2012), though fundamental questions remain regarding the actual trigger in humans and experimental model systems (Macefield et al., 2012).
Additional autonomic functions are served and mediated by the vagal system, which is not directly impacted by experimental SCI and most clinical SCI. This vital and widespread system is nonetheless affected by SCI in terms of changes to electrical and chemical properties of neurons and changes in their connectivity (Kaddumi and Hubscher, 2007a,b; Holmes, 2012).

\section{PAIN MECHANISMS AND TREATMENT}

Chronic pain is not a consequence of SCI that is obvious to the casual observer, yet it is one of the most common postSCI conditions and most impactful on the quality of life of SCI individuals (e.g., Finnerup and Baastrup, 2012). There are numerous mechanisms by which SCI-related pain can arise, some of which we are only now identifying, yet these are still poorly understood and there are few reliable treatments (e.g., Felix et al., 2007; Cruz-Almeida et al., 2009). The effect of SCI on primary sensory neurons is an emerging topic of investigation (Huang et al., 2006; Shortland et al., 2006; Ramer et al., 2012; Walters, 2012) as a possible mechanism of SCI-related pain and other pathologies such as AD (e.g., Widerstrom-Noga et al., 2004). New approaches to applying knowledge of nociceptive mechanisms are also being tested as potential treatments for SCI-related sensory pathologies (Gupta and Hubscher, 2012; Lee et al., 2012; Rabchevsky et al., 2012; Ramer et al., 2012).

\section{EFFECTS OF POST-SCI TRAINING}

In addition to a variety of forms of maladaptive plasticity, the spinal cord caudal to an injury which largely or completely separates it from the brain is capable of considerable and lasting adaptive plasticity, particularly activity-dependent plasticity (e.g., Edgerton et al., 1992; Hodgson et al., 1994; De Leon et al., 1999; Edgerton et al., 2001; Frigon and Rossignol, 2006), with some of this plasticity involving the sensory neurons (e.g., De Leon et al., 2001; Petruska et al., 2007). The spinal cord is capable of interpreting afferent input to learn a task and to counter perturbing forces or avoid obstacles placed in the path of hindlimbs stepping on a treadmill, and even retaining this information for a short time without reinforcement (Zhong et al., 2012). This collective work suggests that the spinal cord is capable of learning (see also Ferguson et al., 2012a,b; Grau et al., 2012), and may be capable of processes akin to formation of short- and long-term memory.

Generally the effects of training appear to be task-specific. For example, when an SCI animal is trained to step on a treadmill, this behavior improves, but the performance of other 
tasks, such as standing, does not improve (Edgerton et al., 1997; De Leon et al., 1998, 1999). However, training does appear to have effects on some processes outside of the trained task. In animal models there are demonstrations of reduced spasticity (Bose et al., 2012), and reduced nociception (Wolpaw and Tennissen, 2001; Hutchinson et al., 2004; Martin Ginis and Latimer, 2007; Herrity et al., 2012).

More recently, principles identified from animal experiments have been applied to human experiments and clinical treatment with some success (Behrman et al., 2005; Barbeau et al., 2006; Dobkin et al., 2006; Harkema, 2008; Edgerton and Roy, 2009; Harkema et al., 2011). However, the field still has much to discover in terms of the characteristics of spinal plasticity, the necessary and sufficient influencing factors, as well as certain measures of systems, molecular, and cellular mechanisms that enable, facilitate, and inhibit such adaptive plasticity.

\section{MECHANISMS REGULATING SPINAL LEARNING}

Research on post-SCI training focuses on optimizing functional recovery and identifying relevant principles from the sensorimotor integration perspective. Another approach has examined the principles of learning that may be at play in the spinal cord (Ferguson et al., 2012a,b; Grau et al., 2012), with important concepts emerging about extrinsic factors interfering with successful spinal learning (i.e., training). Given the relative success of activity-based therapies in both animal and human experiments and the significant effort and resources dedicated to optimizing these approaches for clinical gain, we must also identify factors that inhibit recovery (e.g., Caudle et al., 2011; Ferguson et al., 2012a,b).

In this context it is intriguing that many clinical trials have exclusion criteria related to conditions that would be painful for spinal-intact individuals (bladder infection, pressure ulcer, tissue damage, etc.). Common among front-line therapists are anecdotes of discovering skin abrasions, treadmill harnesses pinching skin, bladder infections, and other covert noxious conditions in patients whose training sessions were unexpectedly going poorly. These anecdotes suggest that the powerful influence of the spinal nociceptive system on the spinal motor system known from animal work is also at play in SCI patients/subjects. Unfortunately, these accounts are not regularly included in data collection, limiting assessments of the role of nociception in activity-dependent therapies.

These concepts may be involved in other spinal processes. For example, systems that are accustomed to a certain level

\section{REFERENCES}

Barbeau, H., Basso, M., Behrman, A., and Harkema, S. (2006). Treadmill training after spinal cord injury: good but not better. Neurology 67, 1900-1901. author reply: 1901-1902. doi: 10.1212/01.wnl. $0000249080.15391 .6 \mathrm{~d}$

Behrman, A. L., Lawless-Dixon, A. R., Davis, S. B., Bowden, M. G., Nair, P., Phadke, C., et al. (2005). Locomotor training progression and outcomes after incomplete spinal cord injury. Phys. Ther. 85, 1356-1371.

Bose, P. K., Hou, J., Parmer, R., Reier, P. J., and Thompson, F. J. (2012). Altered patterns of reflex excitability, balance, and locomotion following spinal cord injury and locomotor training. Front. Physiol. 3:258. doi: 10.3389/fphys. 2012.00258

and pattern of activity can "fall out of tune" (e.g., LundbyeJensen and Nielsen, 2008). Also, growth of nociceptive afferent terminals within the cord contributes to $\mathrm{AD}$ (e.g., Cameron et al., 2006; Brown and Weaver, 2012). However, repetitive natural stimulation, determined to be accompanied by intraspinal sprouting of afferents, reduces nociceptive reflexes (Conde and Komisaruk, 2012). Collectively this suggests that the functional outcome of intraspinal afferent growth may be dependent on the pattern of information carried by those afferents and the context of the intraspinal growth. Perhaps intraspinal growth that is uncoupled from specific patterned input becomes maladaptive, while growth associated with patterned input is associated with adaptive outcomes [Conde and Komisaruk, 2012; Ferguson et al., 2012a,b; Grau et al., 2012; and discussed in Petruska et al. (2007) and Maier et al. (2009)].

\section{EFFECTS OF SCI ON NEURAL TISSUE REMOTE FROM THE INJURY}

Considering points of similarity and difference among experimental observations makes it clear that many characteristics of the injury model can have significant impact on the outcomes being measured (e.g., Cote et al., 2012; Hougland et al., 2012). Injury to one part of the spinal cord can have significant impact on systems that were not directly affected (Cote et al., 2012). The nervous system is particularly susceptible to such bystander effects because of the close physical proximity of neurons involved in diverse functions and the array of circuit interconnections, some of which may not be obvious until there is an injury. It is therefore beneficial to consider multiple elements of a system (such as examining sensory neurons and the spinal cord together when considering sensorimotor responses to SCI), as they can act differently in response to the same injury (Hougland et al., 2012).

The SCI condition involves pathologies beyond the spinal cord itself and the spinal cord disconnected from the brain can still generate output which relies heavily on the input it receives from the periphery. Understanding the status of the afferents providing input to the spinal cord and brainstem is of paramount importance. If the "below-level" spinal cord and the post-SCI vagal system are to be maintained in a healthy condition, then we must understand the vital roles that gateway primary afferent neurons play in both acute and chronic post-SCI pathologies in order to prevent sensory-based pathologies and direct these neurons to enhance recovery of function.

Brown, A., and Weaver, L. C. (2012). The dark side of neuroplasticity. Exp. Neurol. 235, 133-141. doi: 10.1016/j.expneurol. 2011.11.004

Cameron, A. A., Smith, G. M., Randall, D. C., Brown, D. R., and Rabchevsky, A. G. (2006). Genetic manipulation of intraspinal plasticity after spinal cord injury alters the severity of autonomic dysreflexia.
J. Neurosci. 26, 2923-2932. doi: 10.1523/JNEUROSCI.4390-05.2006 Caudle, K. L., Brown, E. H., Shum-Siu, A., Burke, D. A., Magnuson, T. S., Voor, M. J., et al. (2011). Hindlimb immobilization in a wheelchair alters functional recovery following contusive spinal cord injury in the adult rat. Neurorehabil. Neural Repair 25, 729-739. doi: $10.1177 / 1545968311407519$ 
Chau, D., Johns, D. G., and Schramm, L. P. (2000). Ongoing and stimulus-evoked activity of sympathetically correlated neurons in the intermediate zone and dorsal horn of acutely spinalized rats. J. Neurophysiol. 83, 2699-2707.

Claydon, V. E., Steeves, J. D., and Krassioukov, A. (2006). Orthostatic hypotension following spinal cord injury: understanding clinical pathophysiology. Spinal Cord 44, 341-351. doi: 10.1038/sj.sc.3101855

Conde, D., and Komisaruk, B. R. (2012). A neuroanatomical correlate of sensorimotor recovery in response to repeated vaginocervical stimulation in rats. Front. Physiol. 3:100. doi: 10.3389/fphys.2012.00100

Cote, M. P., Detloff, M. R., Wade, R. E. Jr., Lemay, M. A., and Houle, J. D. (2012). Plasticity in ascending long propriospinal and descending supraspinal pathways in chronic cervical spinal cord injured rats. Front. Physiol. 3:330. doi: 10.3389/fphys.2012.00330

Cruz-Almeida, Y., Felix, E. R., Martinez-Arizala, A., and Widerstrom-Noga, E. G. (2009). Pain symptom profiles in persons with spinal cord injury. Pain Med. 10, 1246-1259. doi: 10.1111/j.1526-4637.2009.00713.x

De Leon, R. D., Hodgson, J. A., Roy, R. R., and Edgerton, V. R. (1998). Full weight-bearing hindlimb standing following stand training in the adult spinal cat. J. Neurophysiol. 80, 83-91.

De Leon, R. D., Hodgson, J. A., Roy, R. R., and Edgerton, V. R. (1999). Retention of hindlimb stepping ability in adult spinal cats after the cessation of step training. J. Neurophysiol. 81, 85-94.

De Leon, R. D., Roy, R. R., and Edgerton, V. R. (2001). Is the recovery of stepping following spinal cord injury mediated by modifying existing neural pathways or by generating new pathways. a perspective. Phys. Ther. 81, 1904-1911.

Dobkin, B., Apple, D., Barbeau, H., Basso, M., Behrman, A., Deforge, D., et al. (2006). Weight-supported treadmill vs over-ground training for walking after acute incomplete SCI. Neurology 66, 484-493. doi: 10.1212/ 01.wnl. 0000202600. 72018.39

Edgerton, V. R., De Leon, R. D., Tillakaratne, N., Recktenwald, M. R., Hodgson, J. A., and Roy, R. R. (1997). Use-dependent plasticity in spinal stepping and standing. $A d v$. Neurol. 72, 233-247.
Edgerton, V. R., Leon, R. D., Harkema, S. J., Hodgson, J. A., London, N., Reinkensmeyer, D. J., et al. (2001). Retraining the injured spinal cord. J. Physiol. 533, 15-22. doi: 10.1111/j.1469-7793. 2001.0015b.x

Edgerton, V. R., and Roy, R. R. (2009). Robotic training and spinal cord plasticity. Brain Res. Bull. 78, 4-12. doi: 10.1016/j.brainresbull.2008.09.018

Edgerton, V. R., Roy, R. R., Hodgson, J. A., Prober, R. J., De Guzman, C. P., and De Leon, R. (1992). Potential of adult mammalian lumbosacral spinal cord to execute and acquire improved locomotion in the absence of supraspinal input. J. Neurotrauma 9(Suppl. 1) S119-S128.

Felix, E. R., Cruz-Almeida, Y., and Widerstrom-Noga, E. G. (2007). Chronic pain after spinal cord injury: what characteristics make some pains more disturbing than others. J. Rehabil. Res. Dev. 44, 703-715. doi: 10.1682/JRRD.2006.12.0162

Ferguson, A. R., Huie, J. R., Crown, E. D., Baumbauer, K. M., Hook, M. A., Garraway, S. M., et al. (2012a). Maladaptive spinal plasticity opposes spinal learning and recovery in spinal cord injury. Front. Physiol. 3:399. doi: 10.3389/fphys.2012.00399

Ferguson, A. R., Huie, J. R., Crown, E. D., and Grau, J. W. (2012b). Central nociceptive sensitization vs. spinal cord training: opposing forms of plasticity that dictate function after complete spinal cord injury. Front. Physiol. 3:396. doi: 10.3389/fphys.2012.00396

Finnerup, N. B., and Baastrup, C. (2012). Spinal cord injury pain: mechanisms and management. Curr. Pain Headache Rep. 16, 207-216. doi: 10.1007/s11916-012-0259-x

Frigon, A., and Rossignol, S. (2006). Functional plasticity following spinal cord lesions. Prog. Brain Res. 157, 231-260. doi: 10.1016/S0079-6123(06)57016-5

Grau, J. W., Huie, J. R., Garraway, S. M., Hook, M. A., Crown, E. D., Baumbauer, K. M., et al. (2012). Impact of behavioral control on the processing of nociceptive stimulation. Front. Physiol. 3:262. doi: 10.3389/fphys.2012.00262

Gupta, D. S., and Hubscher, C. H. (2012). Estradiol treatment prevents injury induced enhancement in spinal cord dynorphin expression. Front. Physiol. 3:28. doi: 10.3389/fphys.2012.00028
Harkema, S., Gerasimenko, Y., Hodes, J., Burdick, J., Angeli, C., Chen, Y., et al. (2011). Effect of epidural stimulation of the lumbosacral spinal cord on voluntary movement, standing, and assisted stepping after motor complete paraplegia: a case study. Lancet 377, 1938-1947. doi: 10.1016/S0140-6736(11)60547-3

Harkema, S. J. (2008). Plasticity of interneuronal networks of the functionally isolated human spinal cord. Brain Res. Rev. 57, 255-264. doi: 10.1016/j.brainresrev. 2007.07.012

Herrity, A. N., Ward, P. J., Harkema S. J. and Hubscher, C. H. (2012) "Locomotor training time affects atlevel allodynia in a rodent model of spinal cord injury," in 2012 Abstract Viewer/Itinerary Planner, 85.18 (New Orleans, LA: Society for Neuroscience).

Hodgson, J. A., Roy, R. R., De Leon, R., Dobkin, B., and Edgerton, V. R. (1994). Can the mammalian lumbar spinal cord learn a motor task. Med. Sci. Sports Exerc. 26, 1491-1497. doi: 10.1249/00005768-19941200000013

Holmes, G. M. (2012). Upper gastrointestinal dysmotility after spinal cord injury: is diminished vagal sensory processing one culprit. Front. Physiol. 3:277. doi: 10.3389/fphys.2012.00277

Hougland, M. T., Harrison, B. J., Magnuson, D. S., Rouchka, E. C., and Petruska, J. C. (2012). The transcriptional response of neurotrophins and their tyrosine kinase receptors in lumbar sensorimotor circuits to spinal cord contusion is affected by injury severity and survival time. Front. Physiol. 3:478. doi: 10.3389/fphys.2012.00478

Huang, W. L., Robson, D., Liu, M. C., King, V. R., Averill, S., Shortland, P. J., et al. (2006). Spinal cord compression and dorsal root injury cause up-regulation of activating transcription factor-3 in large-diameter dorsal root ganglion neurons. Eur. J. Neurosci. 23, 273-278. doi: 10.1111/j.1460-9568.2005.04530.x

Hutchinson, K. J., Gomez-Pinilla, F., Crowe, M. J., Ying, Z., and Basso, D. M. (2004). Three exercise paradigms differentially improve sensory recovery after spinal cord contusion in rats. Brain 127, 1403-1414. doi: 10.1093/brain/awh160

Kaddumi, E. G., and Hubscher, C. H. (2007a). Changes in rat brainstem responsiveness to somatovisceral inputs following acute bladder irritation.
Exp. Neurol. 203, 349-357. doi: 10.1016/j.expneurol.2006.08.011

Kaddumi, E. G., and Hubscher, C. H. (2007b). Urinary bladder irritation alters efficacy of vagal stimulation on rostral medullary neurons in chronic $\mathrm{T} 8$ spinalized rats. J. Neurotrauma 24, 1219-1228. doi: 10.1089/neu.2007.0276

Krassioukov, A. (2004). Autonomic dysreflexia in acute spinal cord injury: incidence, mechanisms, and management. SCI Nurs. 21, 215-216.

Krassioukov, A., and Claydon, V. E. (2006). The clinical problems in cardiovascular control following spinal cord injury: an overview. Prog. Brain Res. 152, 223-229. doi: 10.1016/ S0079-6123(05)52014-4

Krassioukov, A., Warburton, D. E., Teasell, R., and Eng, J. J. (2009). A systematic review of the management of autonomic dysreflexia after spinal cord injury. Arch. Phys. Med. Rehabil. 90, 682-695. doi: 10.1016/j.apmr.2008. 10.017

Krassioukov, A. V., Furlan, J. C., and Fehlings, M. G. (2003). Autonomic dysreflexia in acute spinal cord injury: an under-recognized clinical entity. J. Neurotrauma 20, 707-716. doi: 10.1089/08977150 3767869944

Lee, J. W., Jergova, S., Furmanski, O., Gajavelli, S., and Sagen, J. (2012). Predifferentiated GABAergic neural precursor transplants for alleviation of dysesthetic central pain following excitotoxic spinal cord injury. Front. Physiol. 3:167. doi: 10.3389/fphys.2012.00167

Lundbye-Jensen, J., and Nielsen, J. B. (2008). Immobilization induces changes in presynaptic control of group Ia afferents in healthy humans. J. Physiol. 586, 4121-4135. doi: 10.1113/jphysiol. 2008.156547

Macefield, V. G., Burton, A. R., and Brown, R. (2012) Somatosympathetic vasoconstrictor reflexes in human spinal cord injury: responses to innocuous and noxious sensory stimulation below lesion. Front. Physiol. 3:215. doi: 10.3389/fphys.2012. 00215

Maier, I. C., Ichiyama, R. M., Courtine, G., Schnell, L., Lavrov, I., Edgerton V. R., et al. (2009). Differential effects of anti-nogo-a antibody treatment and treadmill training in rats with incomplete spinal cord injury. Brain 132, 1426-1440. doi: 10.1093/brain/awp085

Martin Ginis, K. A., and Latimer, A. E. (2007). The effects of single 
bouts of body-weight supported treadmill training on the feeling states of people with spinal cord injury. Spinal Cord 45, 112-115. doi: 10.1038/sj.sc.3101911

Petruska, J. C., Ichiyama, R. M., Jindrich, D. L., Crown, E. D., Tansey, K. E., Roy, R. R., et al. (2007). Changes in motoneuron properties and synaptic inputs related to step training after spinal cord transection in rats. J. Neurosci. 27, 4460-4471. doi: 10.1523/JNEUROSCI.230206.2007

Rabchevsky, A. G. (2006). Segmental organization of spinal reflexes mediating autonomic dysreflexia after spinal cord injury. Prog. Brain Res. 152, 265-274. doi: 10.1016/S00796123(05)52017-X

Rabchevsky, A. G., Patel, S. P., Lyttle, T. S., Eldahan, K. C., O'Dell, C. R., Zhang, Y., et al. (2012). Effects of gabapentin on muscle spasticity and both induced as well as spontaneous autonomic dysreflexia after complete spinal cord injury. Front Physiol 3:329. doi: 10.3389/fphys.2012.00329
Ramer, L. M., Van Stolk, A. P., Inskip, J. A., Ramer, M. S., and Krassioukov, A. V. (2012). Plasticity of TRPV1-expressing sensory neurons mediating autonomic dysreflexia following spinal cord injury. Front. Physiol. 3:257. doi: 10.3389/fphys.2012.00257

Schramm, L. P. (2006). Spinal sympathetic interneurons: their identification and roles after spinal cord injury. Prog. Brain Res. 152, 27-37. doi: 10.1016/S0079-6123 (05)52002-8

Shortland, P. J., Baytug, B., Krzyzanowska, A., McMahon, S. B., Priestley, J. V., and Averill, S. (2006). ATF3 expression in L4 dorsal root ganglion neurons after L5 spinal nerve transection. Eur. J. Neurosci. 23, 365-373. doi: 10.1111/j.1460-9568. 2005.04568.x

Taylor, R. F., and Schramm, L. P. (1987). Differential effects of spinal transection on sympathetic nerve activities in rats. Am. J. Physiol. 253, R611-R618.

Teasell, R. W., Arnold, J. M., Krassioukov, A., and Delaney,
G. A. (2000). Cardiovascular consequences of loss of supraspinal control of the sympathetic nervous system after spinal cord injury. Arch. Phys. Med. Rehabil. 81, 506-516. doi: 10.1053/mr.2000.3848

Walters, E. T. (2012). Nociceptors as chronic drivers of pain and hyperreflexia after spinal cord injury: an adaptivemaladaptive hyperfunctional state hypothesis. Front. Physiol. 3:309. doi: 10.3389/fphys.2012. 00309

Widerstrom-Noga, E., Cruz-Almeida, Y., and Krassioukov, A. (2004). Is there a relationship between chronic pain and autonomic dysreflexia in persons with cervical spinal cord injury. J. Neurotrauma 21, 195-204. doi: 10.1089/08977150 4322778659

Wolpaw, J. R., and Tennissen, A. M. (2001). Activity-dependent spinal cord plasticity in health and disease. Annu. Rev. Neurosci. 24, 807-843. doi: 10.1146/annurev. neuro.24.1.807

Zhong, H., Roy, R. R., Nakada, K. K. Zdunowski, S., Khalili, N., De Leon,
R. D., et al. (2012). Accommodation of the spinal cat to a tripping perturbation. Front. Physiol. 3:112. doi: 10.3389/fphys.2012. 00112

Received: 01 August 2013; accepted: 07 August 2013; published online: 27 August 2013.

Citation: Petruska JC, Hubscher $\mathrm{CH}$ and Rabchevsky AG (2013) Challenges and opportunities of sensory plasticity after SCI. Front. Physiol. 4:231. doi: 10.3389/ fphys.2013.00231

This article was submitted to Integrative Physiology, a section of the journal Frontiers in Physiology.

Copyright (C) 2013 Petruska, Hubscher and Rabchevsky. This is an open-access article distributed under the terms of the Creative Commons Attribution License (CC BY). The use, distribution or reproduction in other forums is permitted, provided the original author(s) or licensor are credited and that the original publication in this journal is cited, in accordance with accepted academic practice. No use, distribution or reproduction is permitted which does not comply with these terms. 